\title{
An approach to the chest radiograph
}

I try and spy with my little eye,

Your age, your sex, the name you go by, The type of exam, position you're in, Comparison films? Oh good, let's begin.

Next time can you take a bigger "big breath?" I must see nine ribs at the back of your chest. Your spine's exposed, for all to see,

With clavicles there, it forms a big "T."

No staples, no tubes, no lines on the move, Please don't interrupt! I've just found my groove. Soft tissues look good, your bones, looking great, Keep drinking your milk 'til a hundred-and-eight.

You have a small heart, but that's a good sight, The longer you'll have to give love in your life. Your window AP, as clear as can be,

Your hila are fine, a med student agrees.

No air, down there, subdiaphragm lair, No fluid in angles, no blunting. I swear! Your 'stinum beware, for widening, air, And if it likes left more than right, that's not fair.

And last, but not least, the lungs need a view, Top-bottom, left-right, how ever you do, Check pleural white lines at the edge of the lung, They may show a pneumo' in thin, tall, and young.

No suspected lesions, in any lung regions, Your fissures are clear, my fellow collegian. The req' is unclear, why this scan was done, A clinical correlate would help a tonne!

Regardless, hooray! You're doing okay. Impression: I say, it's a perfect $\mathrm{x}$-ray.

\section{Kedar Patil HBSc}

Class of 2011

Schulich School of Medicine and Dentistry University of Western Ontario London, Ont.

CMAJ 2011. DOI:10.1503/cmaj.101748

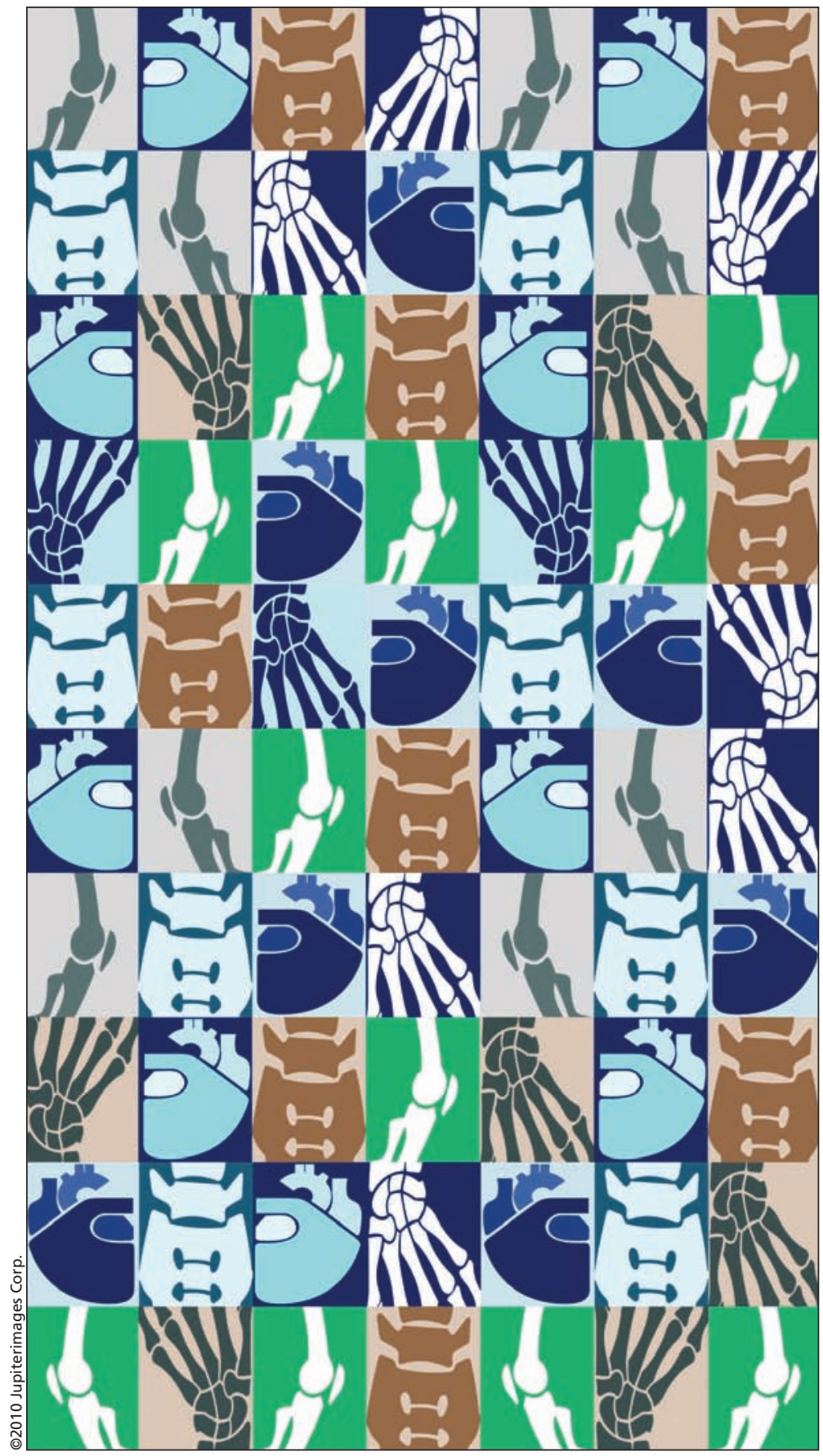

